\title{
A Low-Cost Efficient Hardware-in-the-Loop Testbed for Distributed Generation Penetration Analysis
}

\author{
Kourosh Sedghisigarchi ${ }^{1}$, Yadollah Eslami ${ }^{2}$ and Aasd Davari ${ }^{2}$ \\ 1. Electrical and Computer Engineering Department, California State University, Northridge 91330, USA \\ 2. Electrical and Computer Engineering Department, West Virginia University Institute of Technology, Montgomery 25136, USA
}

Received: December 26, 2016 / Accepted: January 04, 2017 / Published: April 30, 2017.

\begin{abstract}
In this paper a real-time testbed using hardware-in-the-loop for the analysis of the effects of DGs (distributed generators) on microgrids is presented. The distribution network is implemented in SIMULINK using the IEEE 15-node distribution feeder connected to two DGs feeding the grid using two smart inverters. The inverters' active and reactive power control is performed by TI C2000-based controllers and the hardware connections to the system are done through dSPACE interface module. The system is designed such that it can easily be modified to change the location of the DGs and/or to change the number of DGs connected to the grid. Several case study results are presented and compared against simulations to verify the effectiveness and accuracy of the system, model, and the employed power control schemes.
\end{abstract}

Key words: Distributed generation, inverter, real-time control, communication, coordinated control.

\section{Introduction}

As renewable energy generation, such as solar and wind, becomes more affordable, popular, and widespread, more of these small power generators will be connected to the distribution grid at any given time. These DGs (distributed generators) will continuously affect the distribution network state and stability, especially the microgrids [1] which will be the future electric power system infrastructure. Advanced monitoring and control systems are to be deployed in microgrids to avoid issues caused by the uncertainty and variability of the renewable energy sources that feed the DGs and to have a stable and reliable power distribution system [1].

The significant $\mathrm{R} / \mathrm{X}$ ratio in distribution lines suggests the importance of the line resistance; $R$, and its effects on the power flow control on microgrids and microgrid power control equations [2, 3]. Supplying

Corresponding author: Kourosh Sedghisigarchi, Ph.D., assistant professor, research fields: power systems, microgrids, power electronics, renewable energy, smart grids. power from the end users at the end of the line side, however, will reduce on transmission lines and improve voltage and frequency stability, if the DGs are controlled properly. This can be achieved through deployment of inverter-based DGs which can respond to the system variations much faster than their rotation-based generator counter parts. In recent years, significant researches on the control and operation of microgrids have been conducted and both centralized and decentralized control schemes have been proposed and studied [4-9]. The newer generation of inverters used as part of the DGs, called smart inverters, cannot only control the active power, but also the reactive power, and hence, improve the system power factor.

In this paper the development of an HIL (hardware-in-the-loop) system for the analysis and study of the behavior of a distribution network in the presence of two smart-inverter-based DGs is presented. The actual DG voltages are fed to the system using the dSPACE I/O module [10] and all the measurement and communications are performed by the dSPACE Control Desk tool. 
The proposed hardware and software are designed such that they can be easily modified to accommodate more/less DGs on any nodes of the microgrid. The IEEE 15-node distribution feeder model [11, 12] implemented in SIMULINK is the core of the system, augmented by the DG models representing actual local DGs to control the active and reactive power consumption/production at selected nodes and analysis and measurement of penetration levels. The measured and simulated values are compared to verify the validity of the system behavior and the employed power control algorithms in the DGs.

\section{IEEE Distribution Test Feeder}

An inverter power flow control method was presented by authors in Ref. [6] in the grid-connected mode. These inverters operate in low voltage distribution level system where $\mathrm{R} / \mathrm{X}$ ratio of line is much greater compared to transmission system line

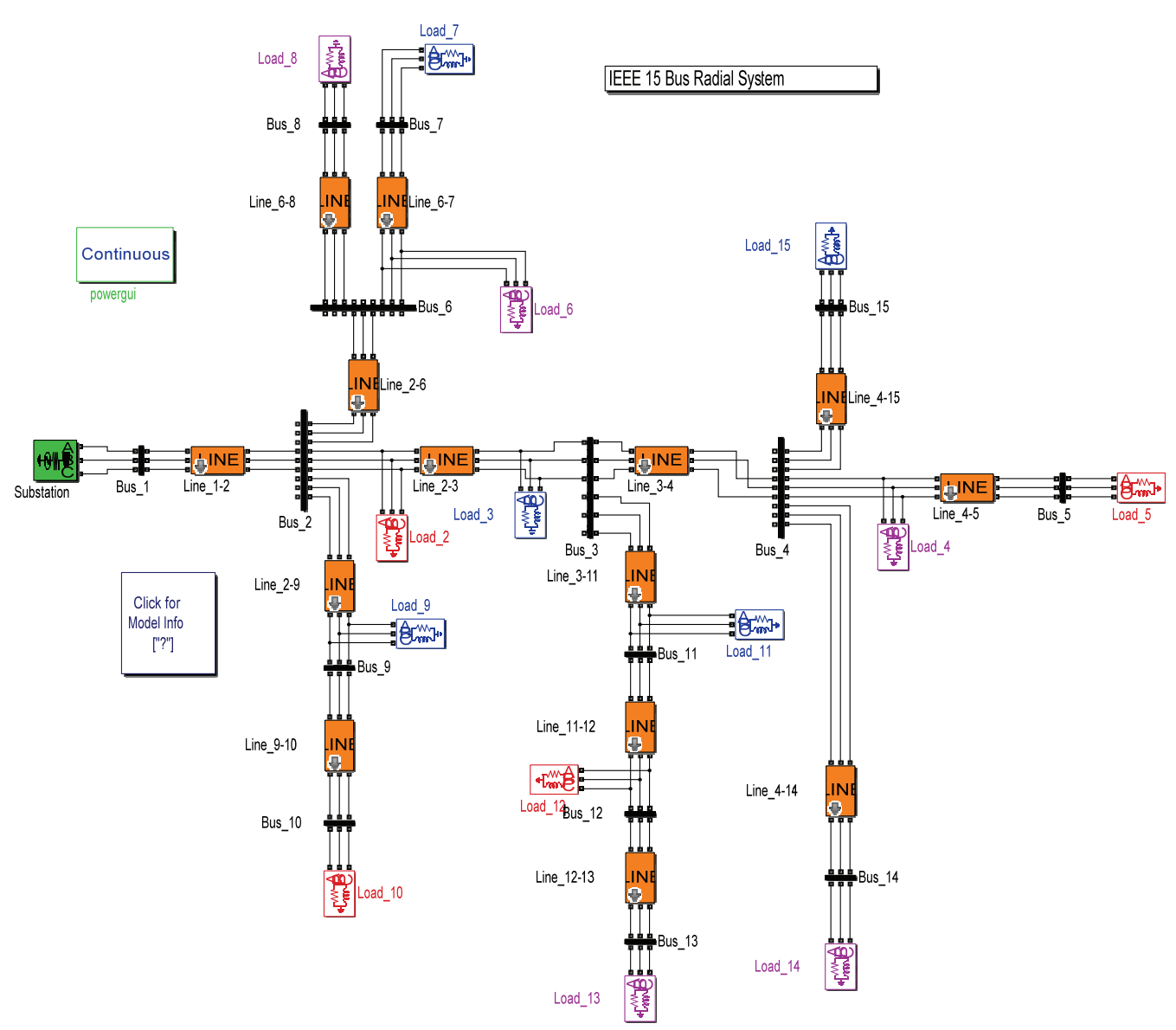

Total losses: parameters. The inverters' active and reactive power control is performed by TI C2000-based controllers and the hardware connections to the system are done through dSPACE interface module. The system is designed such that it can easily be modified to change the location of the DGs and/or to change the number of DGs connected to the grid.

Figs. 1 and 2 indicate the IEEE 15 Bus node feeder [10] developed in MATLAB Simpowersystem toolbox and its voltage profile results $[13,14]$.

Obtained load flow results are as below:

Total generation:

$P=1,177.48 \mathrm{~kW}, Q=1,197.40$ kvar.

Total Zshunt load:

$P=1,126.01 \mathrm{~kW}, Q=1,148.64$ kvar.

$P=51.47 \mathrm{~kW}, Q=47.72 \mathrm{kvar}$.

The model has been simulated for three case studies as follows. 


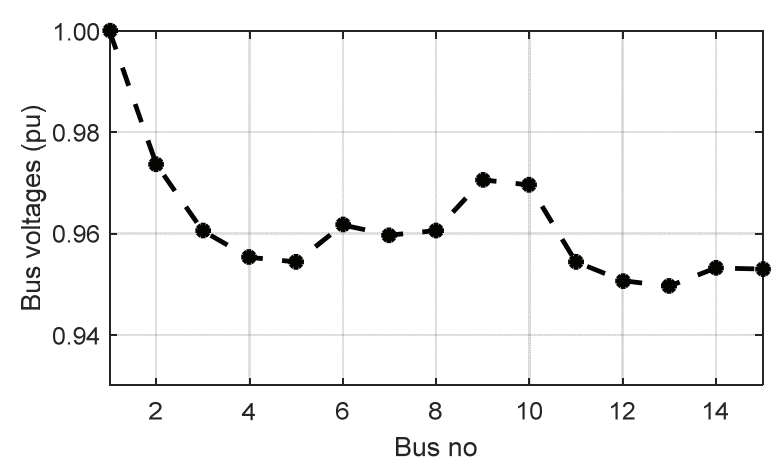

Fig. 2 Voltage profile for IEEE 15-bus distribution network.

\subsection{Case 1: DG1 Is Connected to Bus \#13}

DG1 which is a VSI (voltage source inverter) [15] based distributed generator provides active and reactive power for the following set points:

Case 11: $P 1=120 \mathrm{~kW}, Q 1=30 \mathrm{kvar}$;

Case 12: $P 2=210 \mathrm{~kW} ; Q 2=80$ kvar.

The load voltage profiles for the following case studies is plotted in Fig. 3.

\subsection{Case 2: DG2 Is Connected to Bus \#5}

DG2 which is an inverter based distributed generator provides active and reactive power for the following set points:

Case 21: $P 1=110 \mathrm{~kW}, Q 1=20 \mathrm{kvar}$;

Case 22: $P 2=200 \mathrm{~kW} ; Q 2=80$ kvar.

The load voltage profiles for case studies 21 and 22 are plotted in Fig. 4.

\subsection{Case 3: DG1/DG2 Are Connected to Buses \#5 and \#13}

As shown in Fig. 5, both DG1 and DG2 are feeding power to buses 5 and 13. The load voltage profiles for the following case studies are plotted in Fig. 6 .

Case 31: $P 1=120 \mathrm{~kW}, Q 1=20 \mathrm{kvar}$;

$$
P 2=310 \mathrm{~kW} ; Q 2=20 \mathrm{kvar} ;
$$

Case 32: $P 1=120 \mathrm{~kW}, Q 1=20 \mathrm{kvar}$;

$$
P 2=120 \mathrm{~kW} ; Q 2=50 \mathrm{kvar} \text {. }
$$

\section{Hardware Implementation}

The system hardware is custom designed by authors as proposed in Refs. [7, 9] and depicted in block diagram in Fig. 7.

This set up is a hardware-in-the-loop which includes three main modules:

(1) The inverters;

(2) The inverters' controller;

(3) The grid model.

Inverters, local loads and controllers are hardware modules which are from Labvolt [20] and Texas Instruments. Each inverter is being controlled by a TMS320F28335-based TI (texas instrument) development board [17] that implements the $P-Q$ control algorithm proposed and presented by the authors in Ref. [8].

The test feeder model and measurement devices are depicted in Fig. 8. The test feeder (IEEE 15 bus system) is shown in block $\mathrm{C}$ of Fig. 8. The interface block between the inverters and the grid is a dSPACE DS1104 I/O module which has several analog and digital I/O ports and serial interfaces. This I/O module is the interface between the actual hardware setup and the system model developed in MATLAB.

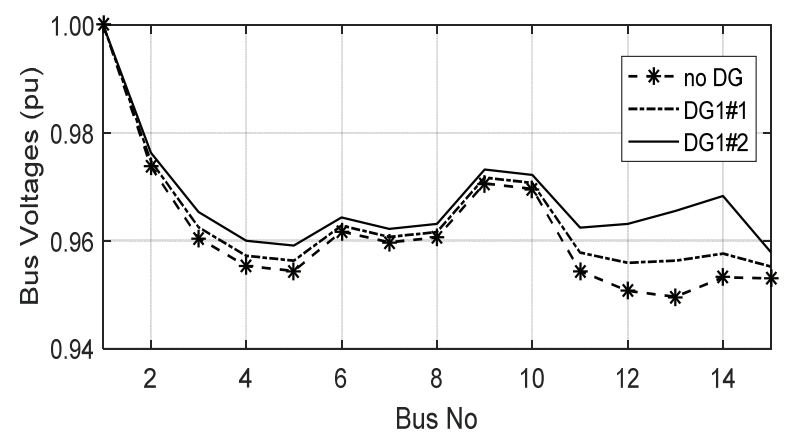

Fig. 3 Voltage profile comparison for case 1.

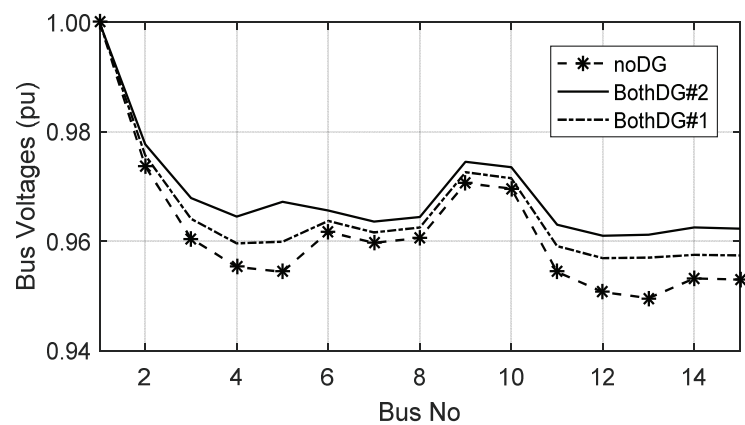

Fig. 4 Voltage profile comparison for case 2. 


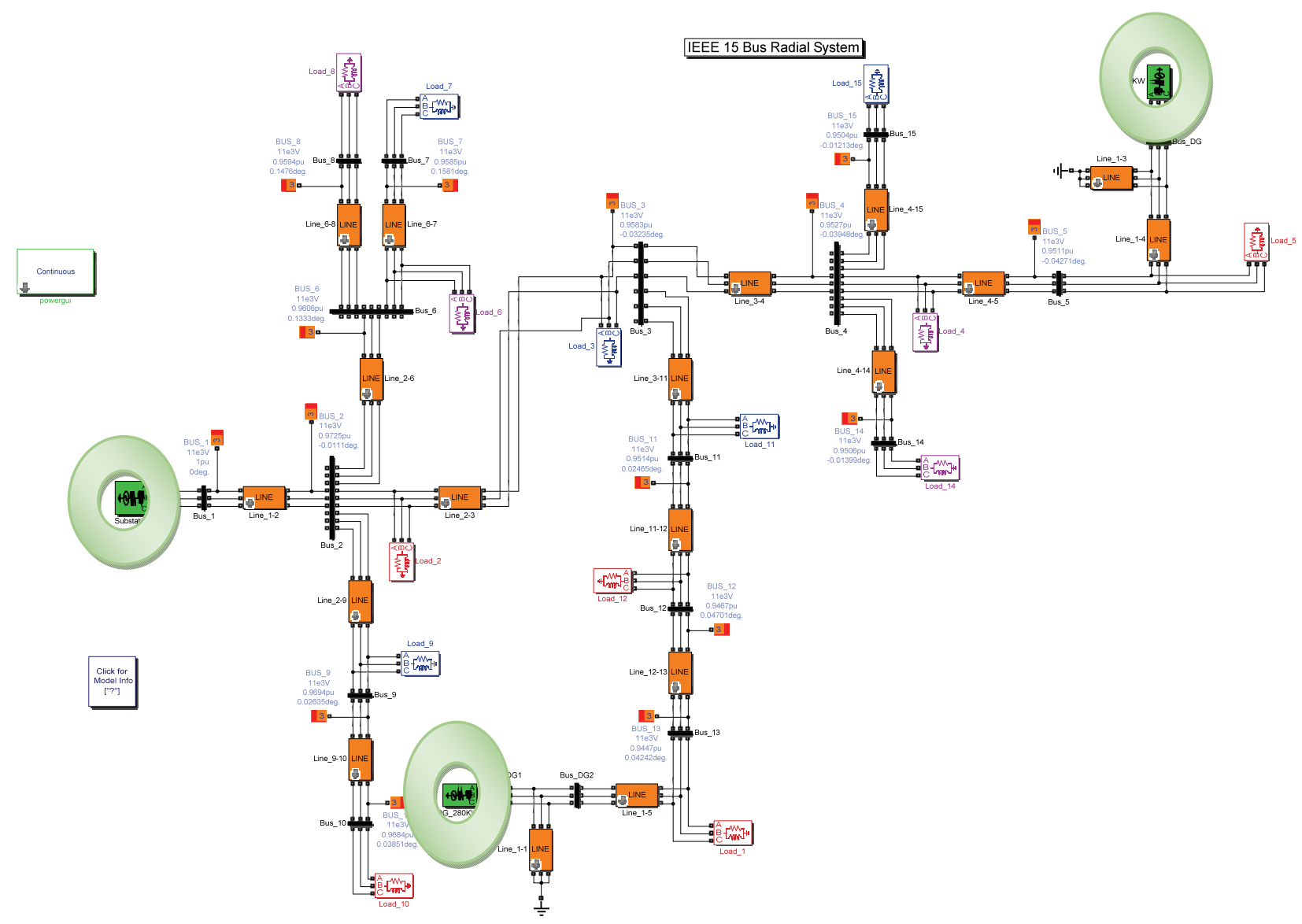

Fig. 5 IEEE distribution feeder with DGs on buses 5 and 13.

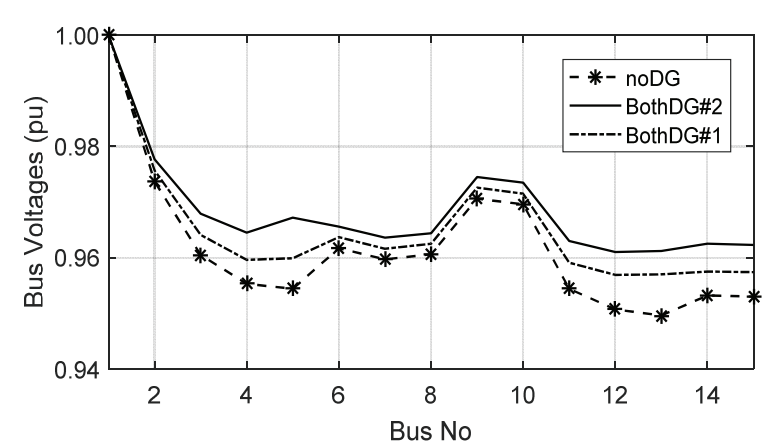

Fig. 6 Voltage distribution profile for case studies.

The test distribution network model is augmented with the measurement devices used at each node for monitoring purposes. As shown in Fig. 8, the voltage and current (to the local load) at each node is measured. The active $(P)$ and reactive $(Q)$ power are calculated at each node load. Notice that as shown in Fig. 8, on this experiment, node 1 of the distribution model is fed by the grid voltage and nodes 5 and 13 by both DG1 and
DG2 inverters, respectively. The grid supply voltage is modeled as a slack bus in the software and its waveform, frequency, and amplitude are accurately set by this approach. Inverters power interfacing sections are

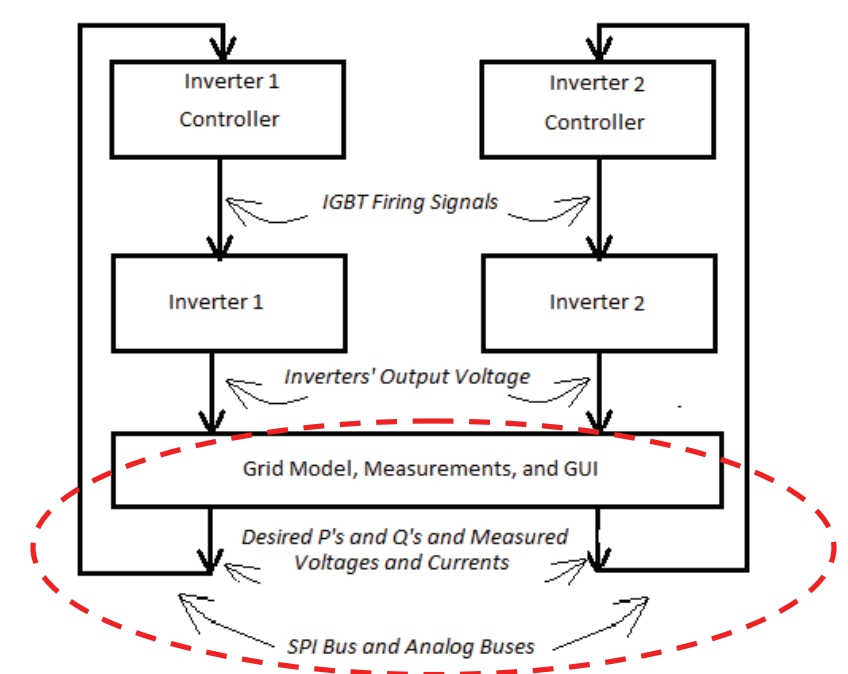

Fig. 7 System hardware block diagram. 


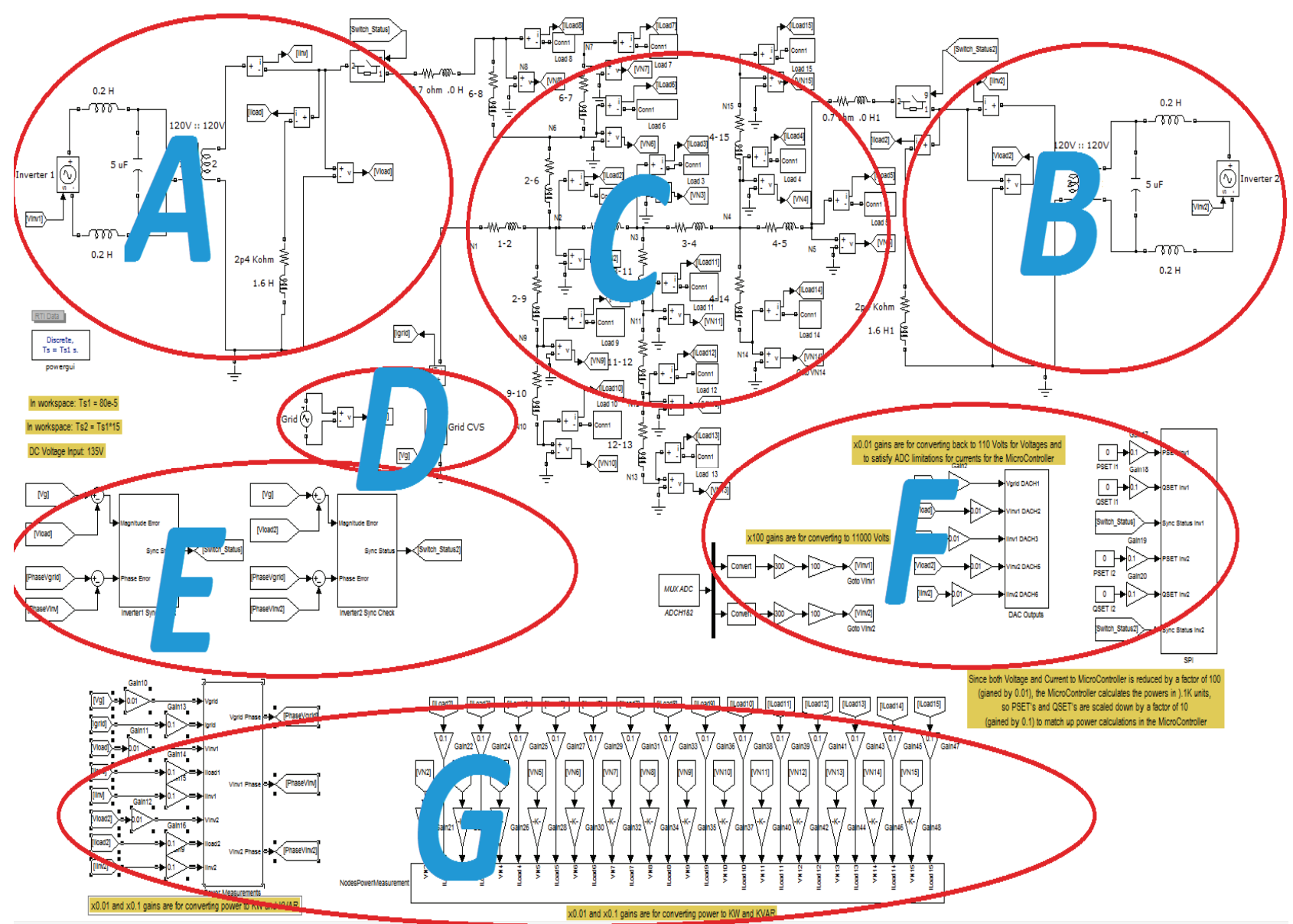

Fig. 8 Simulink model of the system.

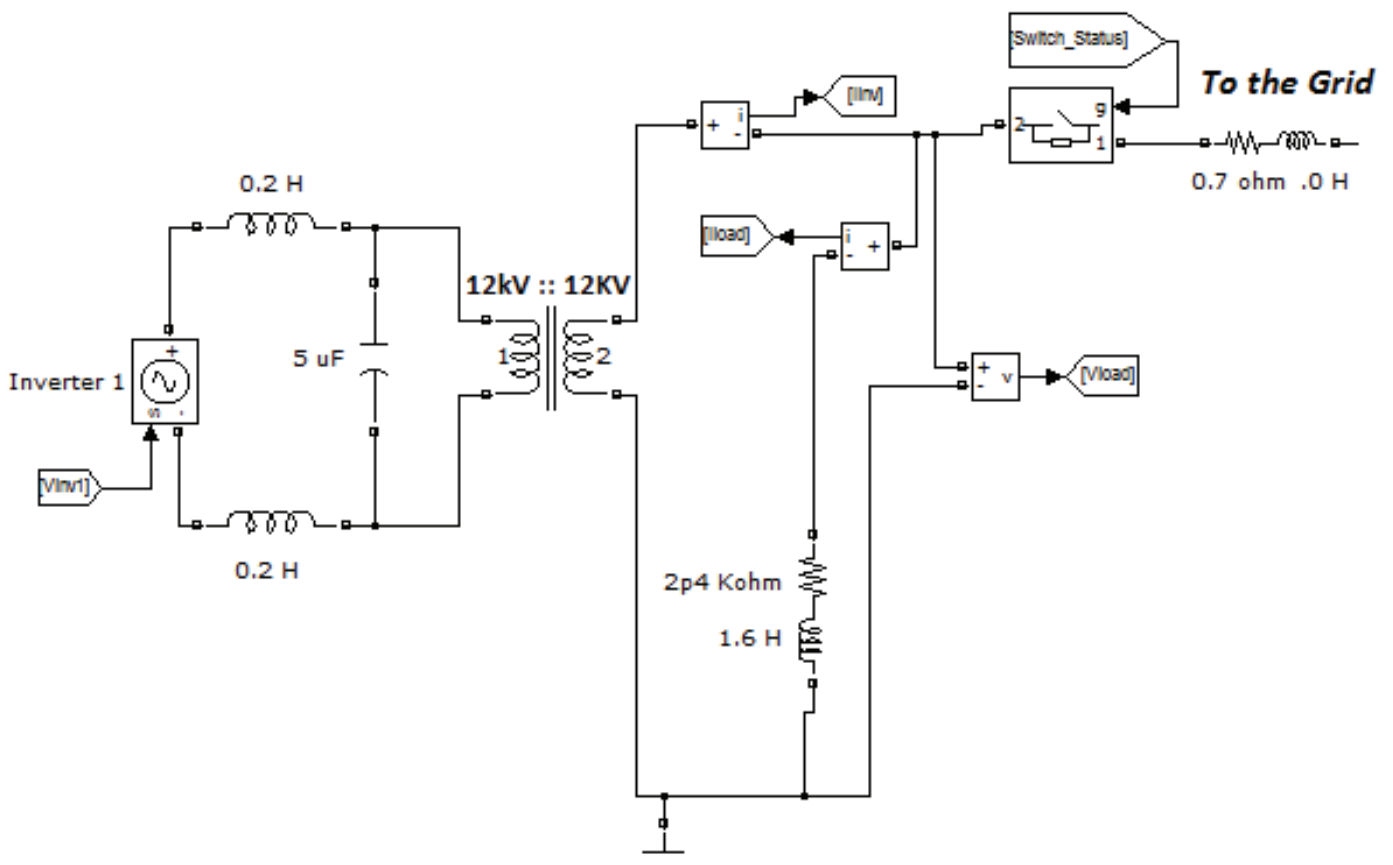

Fig. 9 Inverters power interface section. 


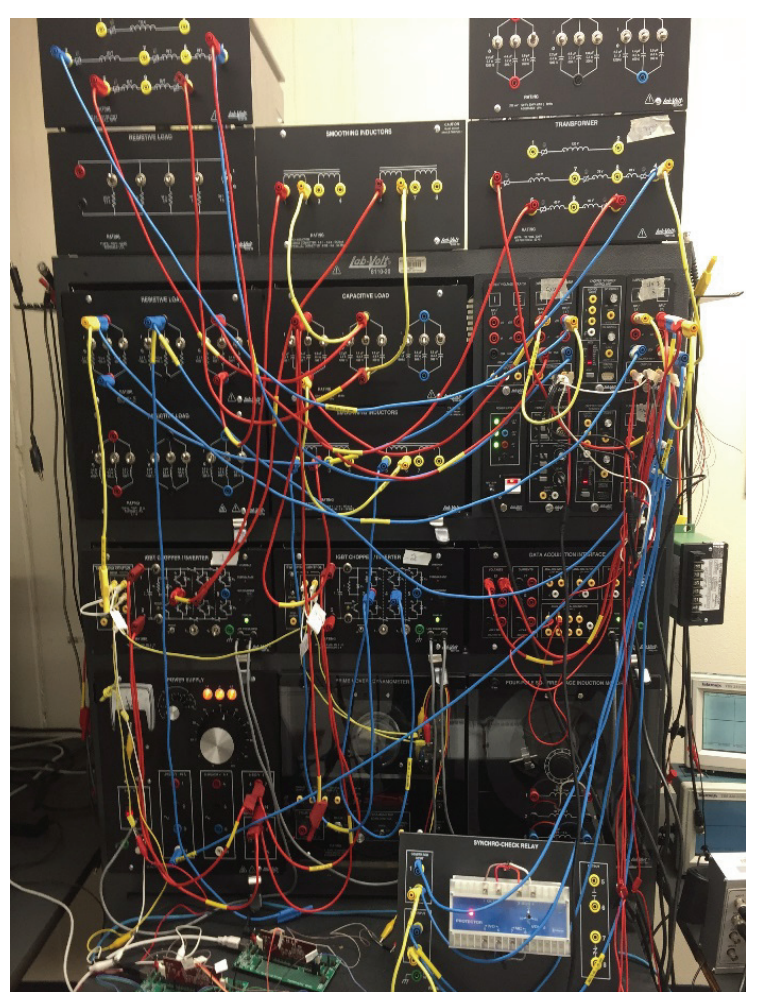

Fig. 10 Developed Hardware-in-the-loop.

presented in Fig. 9. Each inverter output includes a local load and an isolating transformer. The inverters can be isolated or synched to the grid using a breaker module.

Connection to the grid happens when the inverter voltage output at one side of the breaker is synchronized to the voltage of the grid on the other side of the breaker. In order to have the inverter operating at the grid-connected mode, it must be synchronized first. Synchronization blocks used for grid-inverter synchronization are described in Refs. [8, 9].

Fig. 10 shows the hardware system built at the WVUIT (West Virginia University Institute of technology). This work station consists of DC supply, inverter modules, local loads, filters, inverter controllers; step down transducers and connection to the dSPACE I/O module as shown in Fig. 11.

TI Microcontrollers [16-19] are used for synchronization, active and reactive power control (The details of these boards and the algorithms are provided in Refs. [8, 9]).

The system control panel is designed using dSPACE "control desk developer" consisting of three major

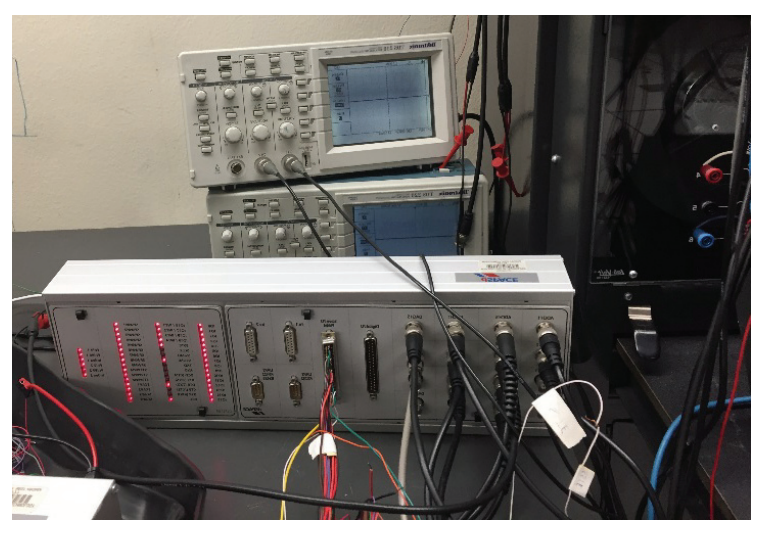

Fig. 11 DSPACE I/O module.

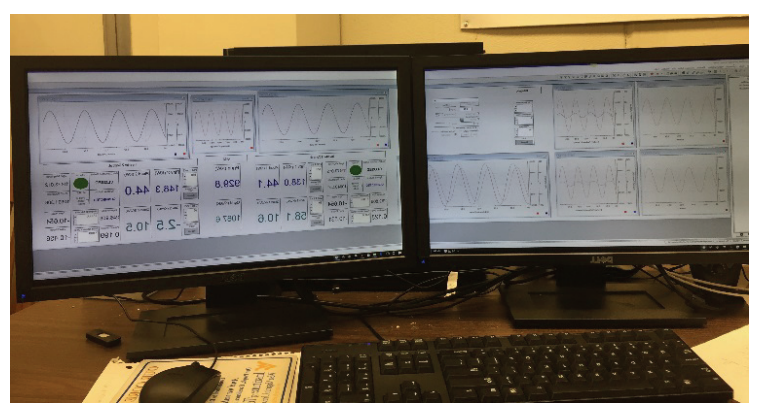

Fig. 12 DSPACE control desk waveforms.

windows that are waveform monitor, inverter monitor and control, node power monitoring windows as shown in Fig. 12 and explained in details in Ref. [11].

\section{Experimental Results}

All simulated case studies presented in Section 2 are tested on the real-time HIL system in this section. The presented infrastructure was capable of handling two simultaneous grid-connected inverters with a sampling interval of $0.0008 \mathrm{~s}$. The power calculations blocks are using a large sampling interval of 0.012 s. Fig. 13 illustrates the control desk window for the test feeder when there is no DG connected.

Figs. 14 and 15 represent DG1 output connected to the bus \#13 while DG2 is isolated and supplying only the local load. The DG1 output is illustrated for the following case studies:

Case 11: $P 1=120 \mathrm{~kW} ; Q 1=30 \mathrm{kvar}$;

Case 12: $P 2=210 \mathrm{~kW} ; Q 2=80$ kvar.

Figs. 16 and 17 represent DG2 output connected to the bus \#5 while DG1 is isolated and supplying only the local load for cases 21 and 22, respectively. 


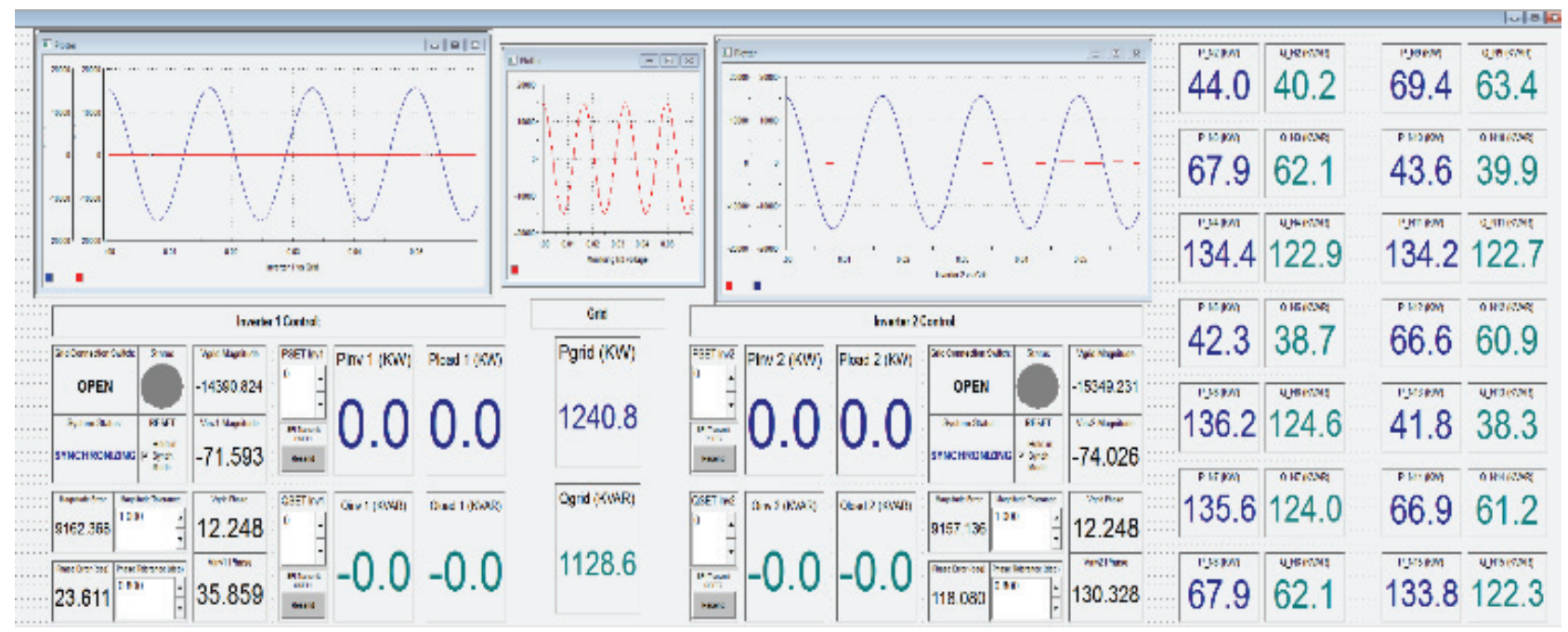

Fig. 13 Grid output with no DGs connected.

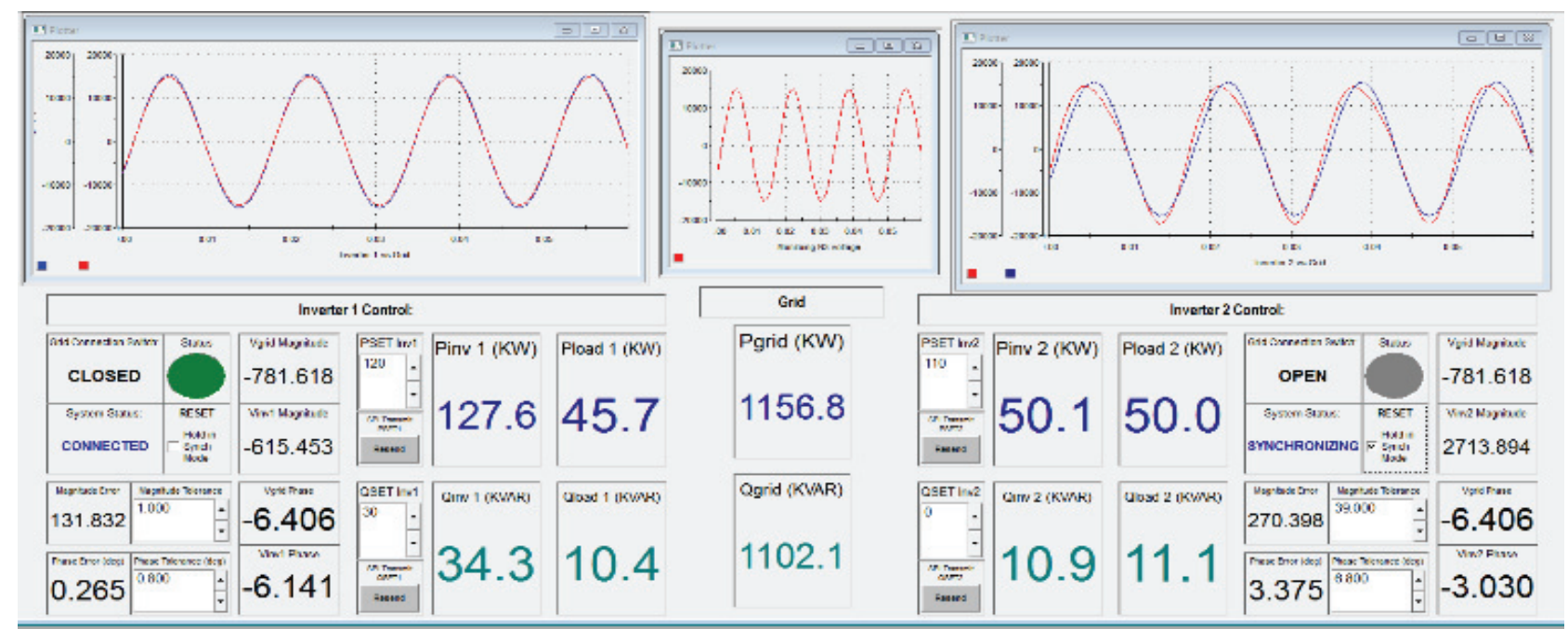

Fig. 14 DG outputs for case \#11.

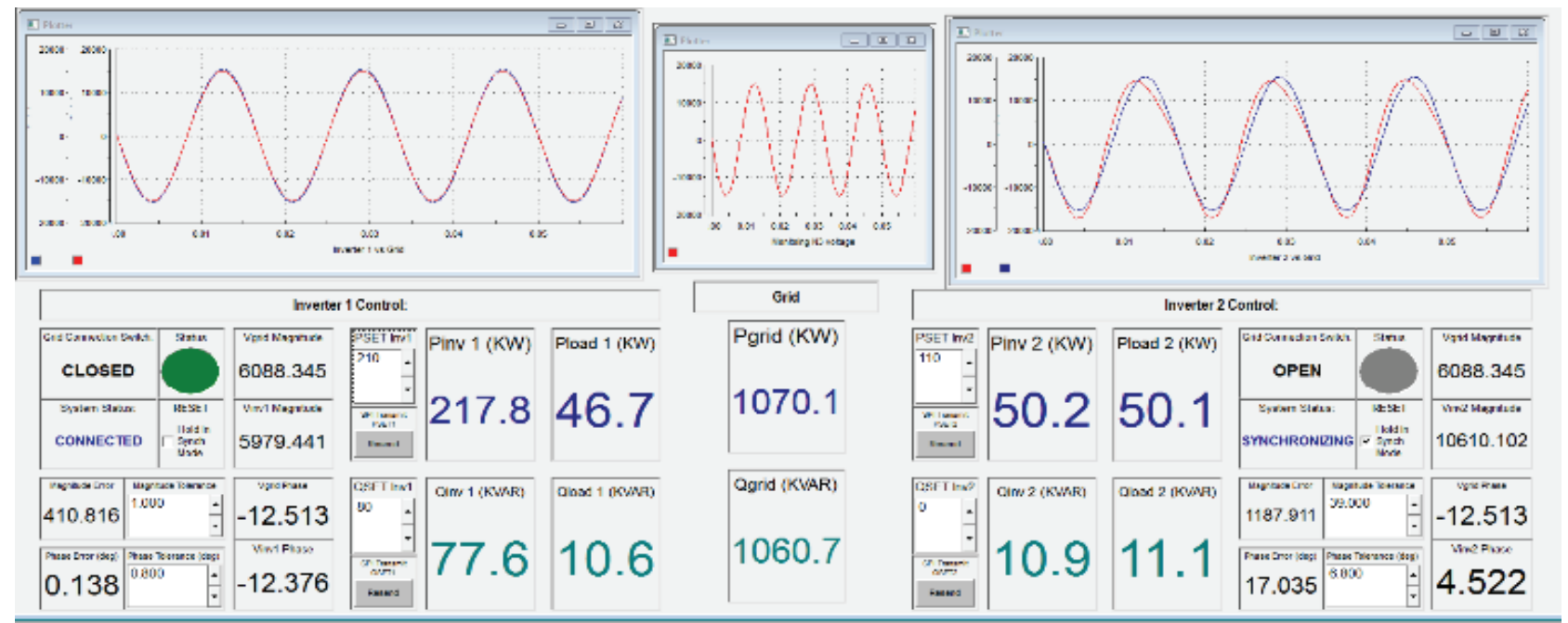

Fig. 15 DG outputs for case \#12. 


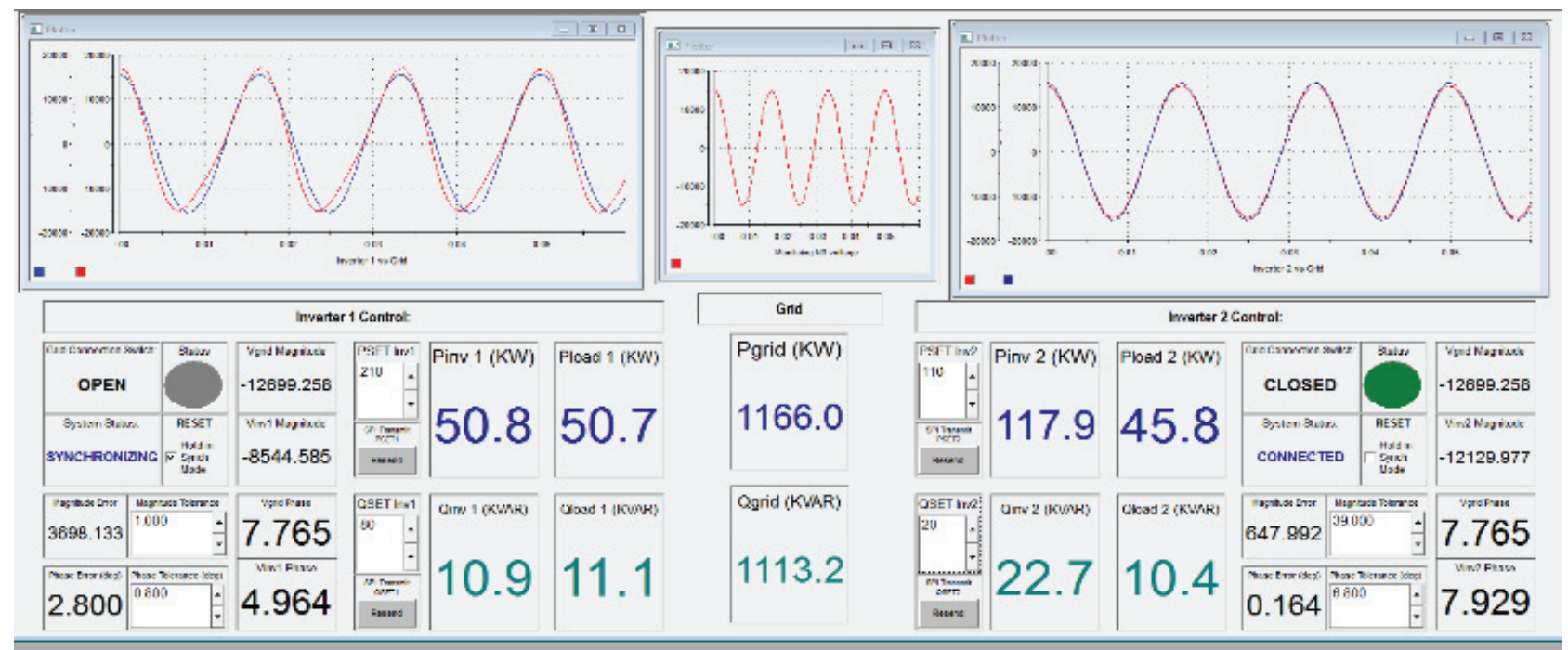

Fig. 16 DG outputs for case 21.

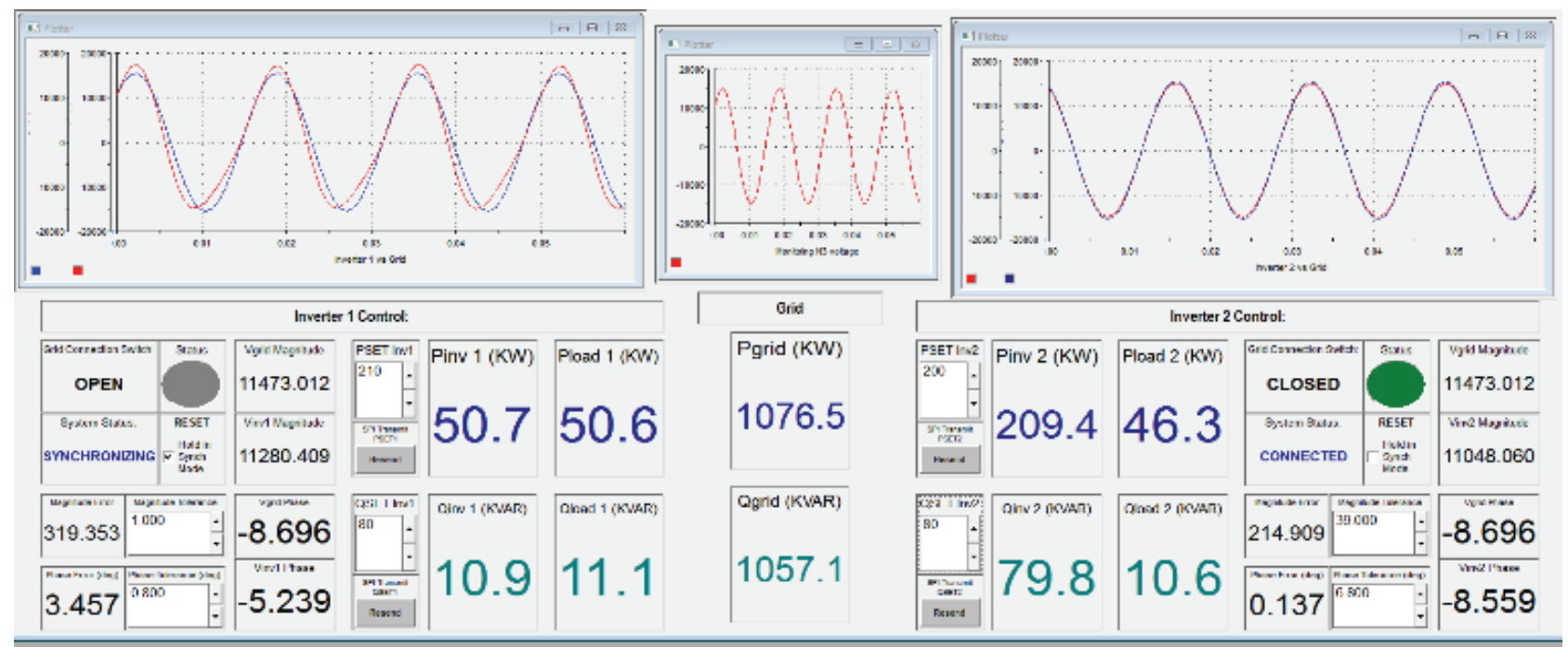

Fig. 17 DG outputs for case 22.

Case 21: $P 1=110 \mathrm{~kW} ; Q 1=20 \mathrm{kvar}$;

Case 22: $P 2=200 \mathrm{~kW} ; Q 2=80 \mathrm{kvar}$.

Figs. 18 and 19 depict system operation for cases 31 and 32 while both DG1 and DG2 outputs are connected to buses 13 and 5, respectively.

Case 31: $P 1=120 \mathrm{~kW} ; Q 1=20 \mathrm{kvar}$;

$P 2=310 \mathrm{~kW} ; Q 2=20 \mathrm{kvar} ;$

Case 32: $P 1=120 \mathrm{~kW} ; Q 1=20 \mathrm{kvar}$;

$P 2=120 \mathrm{~kW} ; Q 2=50 \mathrm{kvar}$.

The output active and reactive power from the main grid ( $\mathrm{P}$ grid, $\mathrm{Q}$ grid) has been shown in the middle of each window in Figs. 13-19.

These figures clearly indicate proper operation of the controller since inverter outputs follow the controller set point. When inverter is isolated, it provides power to the local load only so the synchronization indicator (green light) is off.

\section{Results Comparison}

The grid active and reactive power outputs (P grid, Q grid) have been compared to one another in Table 1 . The simulation and experimental obtained data are very close with a minor error for all case studies. The voltage profile experimental data as well as power flow of the lines showed similar behavior as illustrated in Section 2. 


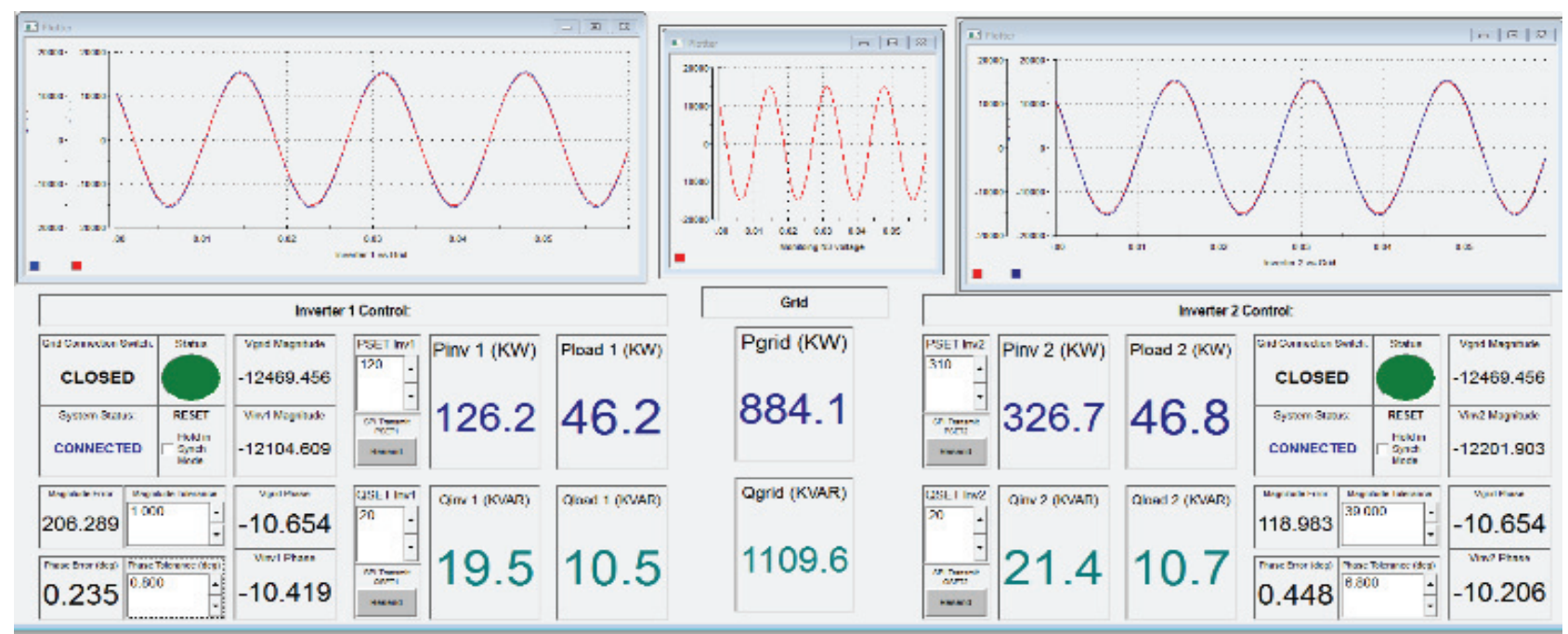

Fig. 18 DG outputs for case 31.

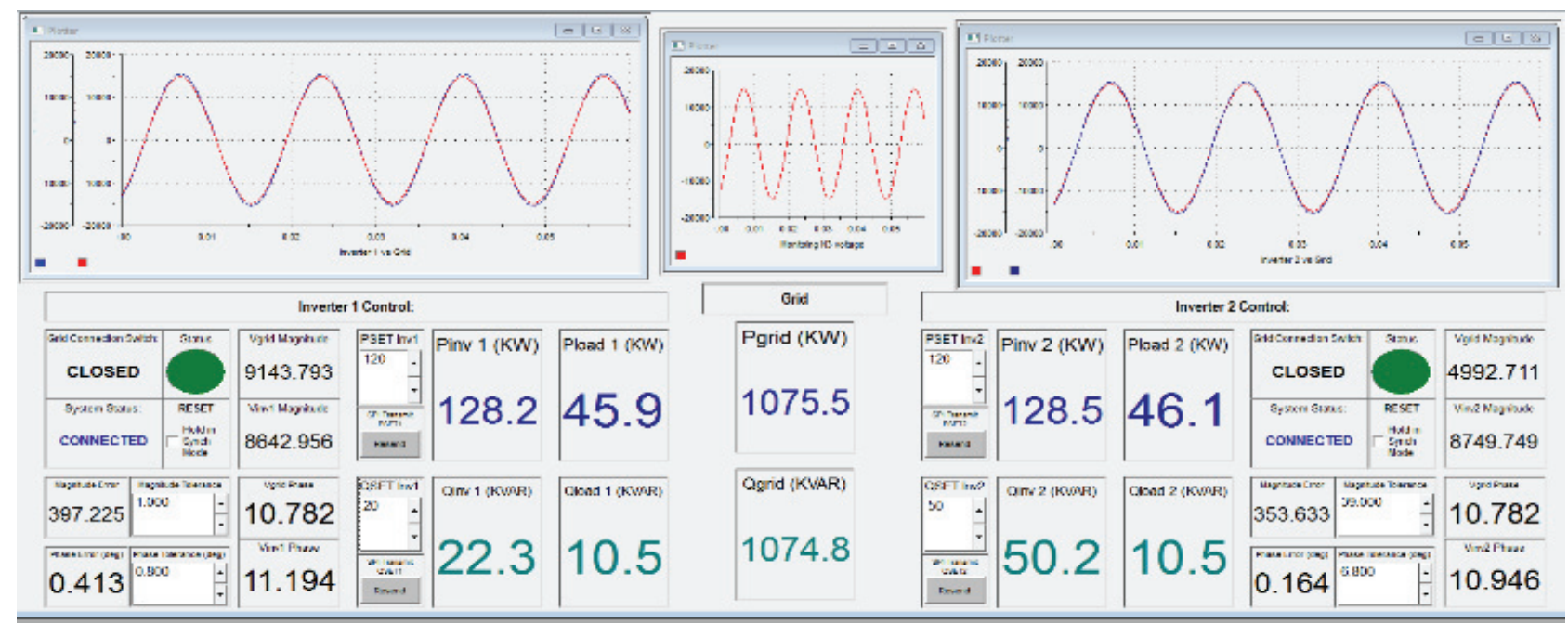

Fig. 19 DG outputs for case 32.

Table 1 Comparison between experimental and simulation results.

\begin{tabular}{lllll}
\hline Case \# & \multicolumn{2}{c}{ Simulation } & \multicolumn{2}{c}{ Experimental } \\
\hline P/Q & $\begin{array}{l}\text { P grid } \\
(\mathrm{kW})\end{array}$ & $\begin{array}{l}\text { P grid } \\
(\mathrm{kW})\end{array}$ & $\begin{array}{l}\text { Q grid } \\
(\mathrm{kvar})\end{array}$ & $\begin{array}{l}\text { Q grid } \\
(\mathrm{kvar})\end{array}$ \\
\hline No DG & 1,177 & 1,200 & 1,128 & 1,197 \\
Case 11 & 1,101 & 1,156 & 1,102 & 1,178 \\
Case 12 & 1,014 & 1,070 & 1,060 & 1,130 \\
Case 21 & 1,120 & 1,166 & 1,113 & 1,190 \\
Case 22 & 1,022 & 1,076 & 1,057 & 1,128 \\
Case 31 & 840 & 884 & 1,109 & 1,183 \\
Case 32 & 1,044 & 1,075 & 1,074 & 1,156 \\
\hline
\end{tabular}

Increase in DG's penetration resulted in less power demand from the main grid in both experimental and simulation modes. In addition, the voltage profile was improved more in buses 5 and 13 due to more power output generation from the distributed generators.

\section{Conclusions}

This paper introduced a real-time hardware-in-the-loop testbed to analyze the impact of distributed generations on low voltage distribution level system where $\mathrm{R} / \mathrm{X}$ ratio is not small. The IEEE 15-bus node distribution feeder has been chosen as the test feeder. Two real time inverter based distributed generators through the dSPACE hardware interface have been connected to the test system. The inverters' active and reactive power control is performed by TI 
C2000-based controllers and the hardware connections to the system are done through dSPACE interface module. The system is designed such that it can easily be modified to change the location of the DGs and/or to change the number of DGs connected to the grid. Several case study results are presented and compared with simulations to verify the effectiveness and accuracy of the system, model, and the employed power control schemes.

\section{References}

[1] Lasseter, R. 2002. "Microgrids." In Proceedings of the IEEE Power Engineering Society Winter Meeting, 305-8.

[2] Peças Lopes, J. A., Silvan, A., Polenz, C. L., and Cherkaoui, M. R. 2010. "Identification of Control and Management Strategies for LV Unbalanced Microgrids with Plugged-in Electric Vehicles." Electric Power Systems Research 80 (8): 898-906.

[3] Li, Y. W., and Kao, Ch.-N. 2009. "An Accurate Power Control Strategy for Power-Electronics-Interfaced Distributed Generation Units Operating in a Low-Voltage Multibus Microgrid.” IEEE Transactions on Power Electronics 24 (12): 2977-88.

[4] Li, Y., and Li, Y. W. 2009. "Decoupled Power Control for an Inverter Based Low Voltage Microgrid in Autonomous Operation." In Proceedings of the IEEE 6th International Power Electronics and Motion Control Conference, 17-20.

[5] Sedghisigarchi, K. 2011. "Power Flow Control of Inverter Based Distributed Generators in LV Microgrids.” IEEE Power \& Society General Meeting, Detroit, MI.

[6] Sedghisigarchi, K., Eslami, Y., and Davari, A. 2012. "A Real-Time Power Controller for Grid-Connected Inverters in LV Smart Microgrids.” 2012 CIGRE Canada Conference, Montreal, ON.

[7] Sedghisigarchi, K., Eslami, Y., and Davari, A. 2013. "A Real-time Power Controller for Grid-Connected Inverters in LV Smart MicroGrids." Journal of Energy and Power Engineering 7 (11): 2156-63.

[8] Sedghisigarchi, K., Eslami, Y., and Davari, A. 2014. "A Real-Time Testbed for Coordinated Control of Inverters in LV Microgrids." IEEE International Energy Conference (ENERGYCON 2014), Dubrovnik, Croatia.

[9] Satyanarayana, S., Ramana, T., Sivanagaraju, S., and Rao, G. K. 2003. "Voltage Stability Analysis for Radial Distribution Networks with and without Compensation." International Journal of Water and Energy 60 (1): 48-53.

[10] DSPACE. $2014 . \quad$ "DSPACE-DS1104." http://www.dspace.com/en/pub/home/products/hw/singbo $\mathrm{rd} / \mathrm{ds} 1104 . \mathrm{cfm}$.

[11] Singh, M., Panigrahi, B. K., Abhynkar, A. R., Mukherjee, R., and Kundu, R. 2013. "Optimal Location, Size and Protection Coordination of Distributed Generation in Distribution Network." IEEE Symposium on Swarm Intelligence.

[12] Sedghisigarchi, K., Eslami, Y., and Davari, A. 2016. “A Hardware in the Loop Testbed for Distributed Energy Generation Penetration Analysis." IEEE Energy Conference, Leuven, Belgium.

[13] MathWorks. $2010 . \quad$ "Simulink." http://www.MathWorks.com/products/simulink.

[14] MathWorks. 2010. "SimPower Systems." http://www.MathWorks.com/products/simpower.

[15] Mohan, N., Undeland, T. M., and Robbins, W. P. 2002. Power Electronics: Converters, Applications, and Design, 3rd Edition. John Wiley and Sons. ISBN: 0-471-22693-9.

[16] Texas Instruments. 2011. “C2000 Real-Time Microcontrollers." Accessed Nov. 2016. http://focus.ti.com/lit/sg/sprb176k/sprb176k.pdf.

[17] Texas Instruments. 2010. "SPRS439I." Accessed Oct. 2016. http://focus.ti.com/lit/ds/sprs439i/sprs439i.pdf.

[18] MathWorks. 2010. "Embedded Coder." Accessed Sep. 2016. http://www.mathworks.com/products/embeddedcoder/index.html.

[19] Texas Instruments. 2010. “CCstudio IDE.” Accessed Sep. 2016. http://focus.ti.com/docs/toolsw/folders/print/ ccstudio.html.

[20] Labvolt. Accessed Nov. 2016. www.labvolt.com. 